Check for updates

Cite this: RSC Adv., 2020, 10, 10447

Received 25th February 2020

Accepted 4th March 2020

DOI: $10.1039 / \mathrm{dOra02026e}$

rsc.li/rsc-advances

\section{Studies on the preparation of aminobipyridines and bipyridine sultams via an intramolecular free radical pathway $\dagger$}

\author{
Javier Recio, Fabiana Filace, Elena Gala, Adrián Pérez-Redondo, Julio Álvarez-Builla* \\ and Carolina Burgos*
}

A variety of aminated bipyridines and bipyridine sultams are prepared by intramolecular radical $[1,5]$-ipso and $[1,6]$-ortho substitutions, using a sulfonamide as a linker to connect the pyridyl radical to the pyridine under attack. For the cases studied, different regiochemistries are observed depending on the initial position of the sulfonamide linker.

\section{Introduction}

Intramolecular aryl and heteroaryl radical addition to arenes represents a valuable and straightforward pathway to access biaryls and heterocyclic aryl derivatives. However, although this radical process has been widely studied in these areas, ${ }^{1 a-h}$ the preparation of an important class of bisheteroaryls, namely bipyridines, has received little attention.

Bipyridines are important scaffolds in many natural alkaloids and synthetic derivatives with a wide range of pharmacological activities (Fig. 1). ${ }^{2 a-g}$ In addition, they are widely used as ligands in organometallic chemistry and are important cores in novel polymeric electro-transporting materials and organic solar cells, amongst others. ${ }^{3 a-d}$ Moreover, although considerable attention has been devoted to the synthesis, study and characterization of dibenzosultams, ${ }^{4 a-j}$ no references have been found for the corresponding bipyridine derivatives.

As part of a research program devoted to studying the bis(hetero)arylation process, via a radical pathway, in the absence of transition metals, we have previously described a new preparation of the bisheterobiaryl sultam 1, which contains a $\beta$-carboline core. The behavior of the starting pyridine sulfonamide 2 was studied under different conditions and only the bisheteroaryl sultam $\mathbf{1}$ was detected under all conditions. ${ }^{5}$

In order to study this cyclization in other related and simpler systems, and to shed some light on this finding, herein we report our studies of radical intramolecular bisheteroarylations

Departamento de Química Orgánica y Química Inorgánica, Instituto de Investigación Química "Andrés M. del Río" (IQAR), Universidad de Alcalá, 28805-Alcalá de Henares, Madrid, Spain.E-mail: carolina.burgos@uah.es

$\dagger$ Electronic supplementary information (ESI) available: Experimental procedures, ${ }^{1} \mathrm{H}$ and ${ }^{13} \mathrm{C}$ NMR spectra for new compounds and X-ray crystallographic analysis for 5ba (PDF). CCDC 1967009. For ESI and crystallographic data in CIF or other electronic format see DOI: 10.1039/d0ra02026e in the presence of tris(trimethylsilyl)silane and azobisisobutyronitrile (TTMSS/AIBN), using sulfonamide 3 , which is easy to prepare, as a linker to connect the pyridyl radical to the pyridine under attack, to give bipyridines $\mathbf{4}$ and/or bipyridine sultams $\mathbf{5}$, depending on the initial substitution pattern (Scheme 1).

\section{Results and discussion}

Our work started with the preparation of sulfonamides $\mathbf{3}$, as starting material for the radical cyclization process. According to Motherwell, ${ }^{1 d, 6 a, b}$ Togo $^{7}$ and others, ${ }^{8}$ and taking into consideration our previous work, ${ }^{9}$ it has been shown that the presence of the free $\mathrm{NH}$ can negatively affect the radical arylation reaction by facilitating reduction of the radical generated. In addition, the corresponding group in an $\mathrm{N}$-alkylsulfonamide increases
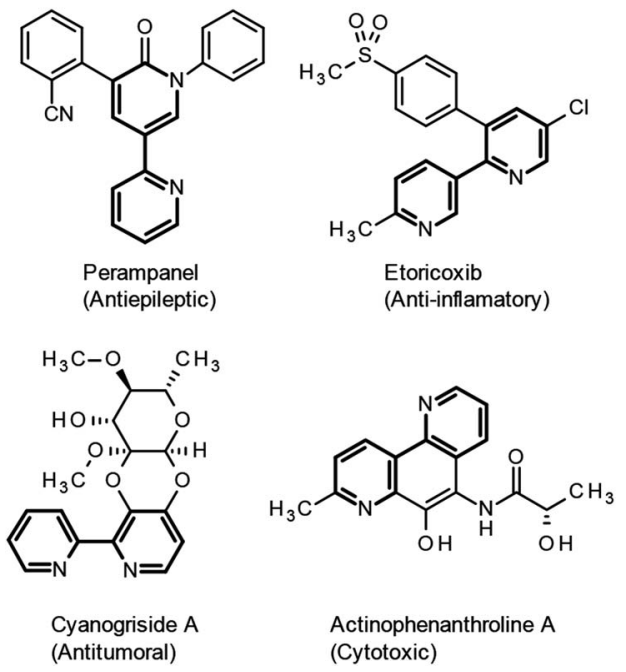

Actinophenanthroline A (Cytotoxic)

Fig. 1 Significant bioactive bipyridines compounds. 


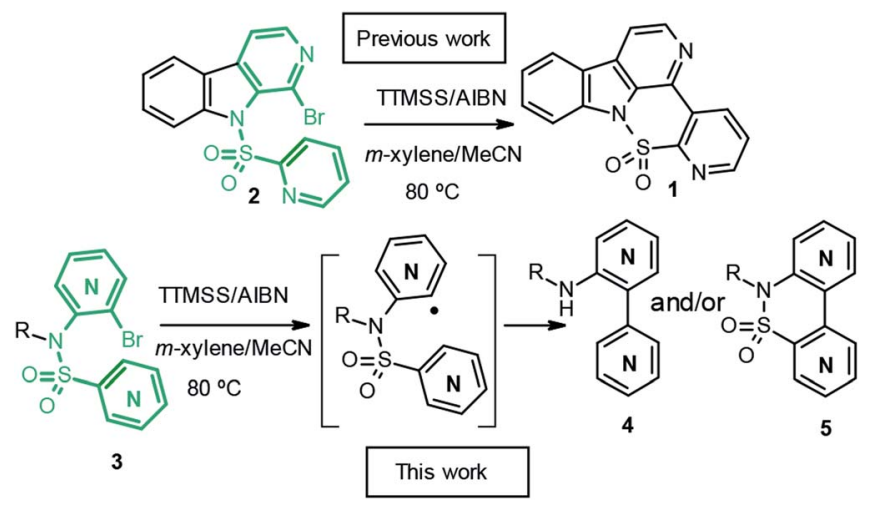

Scheme 1 Background and objectives of this work.

the stiffness of the sulfonamide bond with respect to a free $\mathrm{NH}$, thus meaning that the cis conformation (I versus II, Fig. 2) turns out to be the most suitable for radical cyclization as the radical and the heteroaryl are closest to each other in space. In contrast, although a methyl group is most commonly used for this purpose, it is difficult to remove subsequently, therefore in addition to carrying out our experiments with a methyl group as substituent, we also used MOM (methoxymethyl), which is suitable for protecting sulfonamides but not amines. ${ }^{10}$ Initial experiments were conducted with pyridine 2 -sulfonyl chloride $(\mathbf{6 b})^{11}(\mathrm{X}=\mathrm{CH}, \mathrm{Y}=\mathrm{N}$, Scheme 2) and 2-bromo-3-aminopyridine (7a; $\mathrm{Z}=\mathrm{N}, \mathrm{W}=\mathrm{CH}$, Scheme 2), in refluxing $\mathrm{Et}_{3} \mathrm{~N} / \mathrm{CH}_{2} \mathrm{Cl}_{2}$, although only a $34 \%$ yield of the desired compound $8 \mathbf{c}$ was obtained (Method A).

Even worse results were obtained with the same starting products when using $\mathrm{NaH}$ as the base in refluxing $\mathrm{MeCN}$ or DMF (Method B).

The best results for the formation of sulfonamides $\mathbf{8 a}-\mathbf{c}$, which contain a 2- or 3-aminopyridine core and a sulfonic acid residue formed from the chlorides of $3^{-12}$ or 2-sulfonylpyridine 6, were obtained by addition of 2 equiv. of pyridine sulfonyl chloride to a solution of 1 equiv. of amine in pyridine and stirring the mixture at $80^{\circ} \mathrm{C}$ for $5 \mathrm{~h}$ (Method C). ${ }^{13}$

However, when the same method was applied for the formation of sulfonamide 8d, using pyridine 2-sulfonyl chloride $\mathbf{6 b}$ and the 2 -aminopyridine $\mathbf{7 b}$ as starting products, the desired product was not obtained and the main product was the double sulfonylation derivative $\mathbf{9}$ (Scheme 3). Product $\mathbf{9}$ is likely to be obtained as a consequence of the acidity of the $\mathrm{NH}$ of the sulfonamide in product $\mathbf{8 d}$. Thus, once $\mathbf{8 d}$ has formed, and under the basic conditions of the reaction, the $\mathrm{NH}$ group deprotonates to give the conjugated base of acid III with additional resonance forms $\mathbf{I V}$ and $\mathbf{V}$, in which the negative charge is

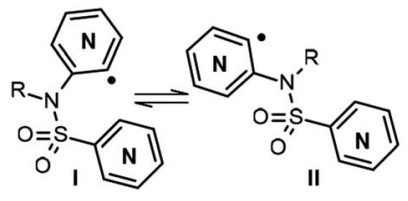

Fig. 2 cis and trans conformations for the sulfonamides radicals.
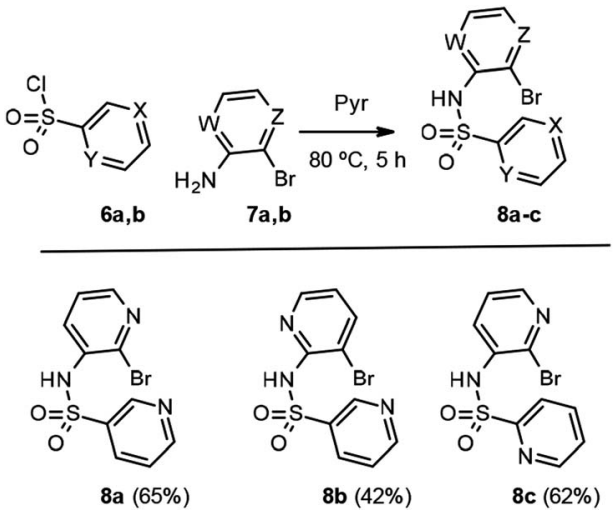

Scheme 2 Synthesis of $8 a-c$

delocalized onto the sulfone group and the endocyclic nitrogen, respectively (Scheme 4).

As this conjugated base is acylated again, the only detectable product is $\mathbf{9}$ (Scheme 3). In view of this finding, and in order to avoid formation of the double sulfonylation product 9 , the reaction between pyridine 2-sulfonyl chloride (6b) and the corresponding $\quad N$-methyl-3-bromo-2-aminopyridines $\quad \mathbf{1 0 a}, \mathbf{b}$ (Scheme 5), prepared by methods previously described in the literature ${ }^{14 a, b}$ was considered as an alternative for the synthesis of pyridines $\mathbf{3 d}$ and $\mathbf{3 e}$. In addition $\mathbf{3} \mathbf{b a}$ was obtained from the methylated aminopyridine 10a. Again, the sulfonylation reaction was carried out with 10a and 10b using Method C, for all cases, giving the corresponding sulfonamides $\mathbf{3 b a}, \mathbf{3 d}$ and $\mathbf{3 e}$ in good yields (Scheme 6). $\mathrm{N}$-Alkylation of sulfonamides $\mathbf{8 a - c}$ was carried out by addition of 1.1 equiv. of sodium hydride to a solution of 1 equiv. of sulfonamides in DMF and subsequent treatment with 1.1 equiv. of methyl iodide or methoxymethyl chloride. Scheme 6 shows our results in this process for $N$-alkyl sulfonamides $\mathbf{3 a a}, \mathbf{3 a b}, \mathbf{3 b b}, \mathbf{3} \mathbf{c a}$ and $\mathbf{3} \mathbf{c b}$, as well as the result for 3ba, $3 d$ and $3 e$.

At this point, we turned our attention to the intramolecular radical bisheteroarylation process, using 3 as starting material and under our optimized conditions, in the presence of tris(trimethylsilyl)silane and azobisisobutyronitrile (TTMSS/AIBN) under thermal conditions. Previous studies by Motherwellid and Chatgilialoglu ${ }^{15}$ suggest that different reaction pathways are

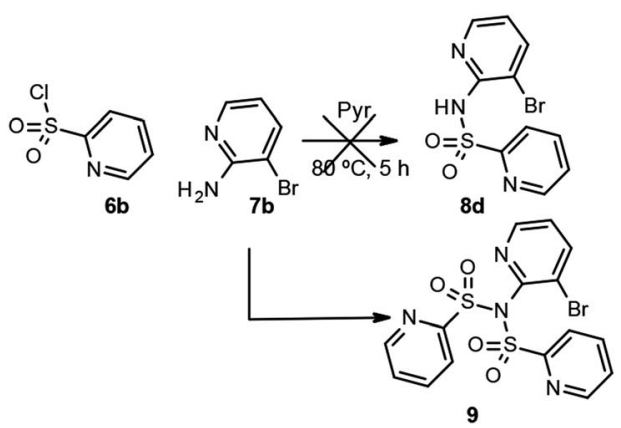

Scheme 3 Reaction of pyridine 2-sulfonyl chloride (6b) in the presence of 3-bromo-2-aminopyridine (7b). 


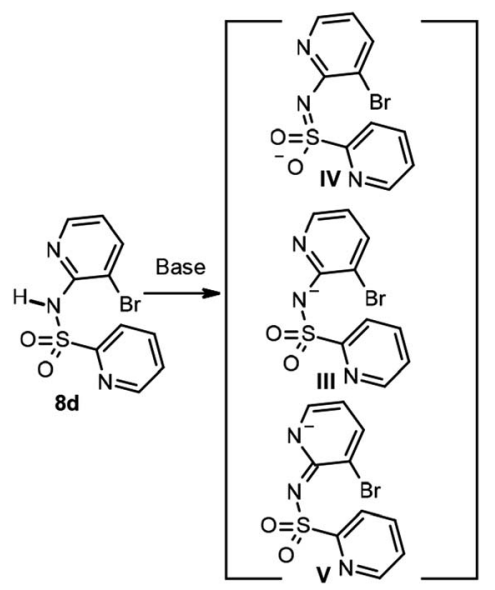

Scheme 4 Proposed in situ deprotonation of pyridine sulfonamide 8d to give the double sulfonylation product 9 .

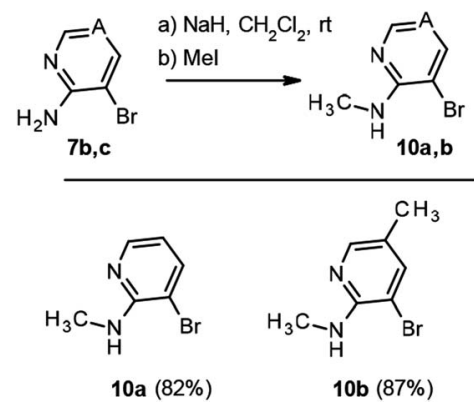

Scheme 5 Methylation of aminopyridines $7 \mathrm{~b}$ and $7 \mathrm{c}$.

possible, depending on the structure of the starting pyridine 3, with the main ones being shown in Scheme 7. Thus, 3ca and 3cb $(\mathrm{X}=\mathrm{CH}, \mathrm{Y}=\mathrm{N}$ and $\mathrm{Z}=\mathrm{N}, \mathrm{A}, \mathrm{W}=\mathrm{CH}$ ) can undergo a non-radical
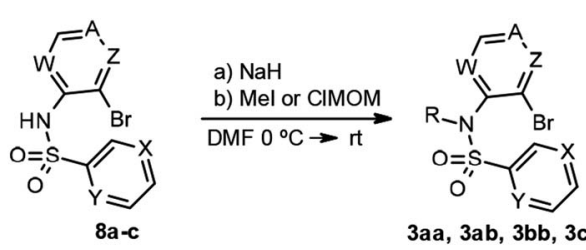

3aa, 3ab, 3bb, 3ca, 3cb
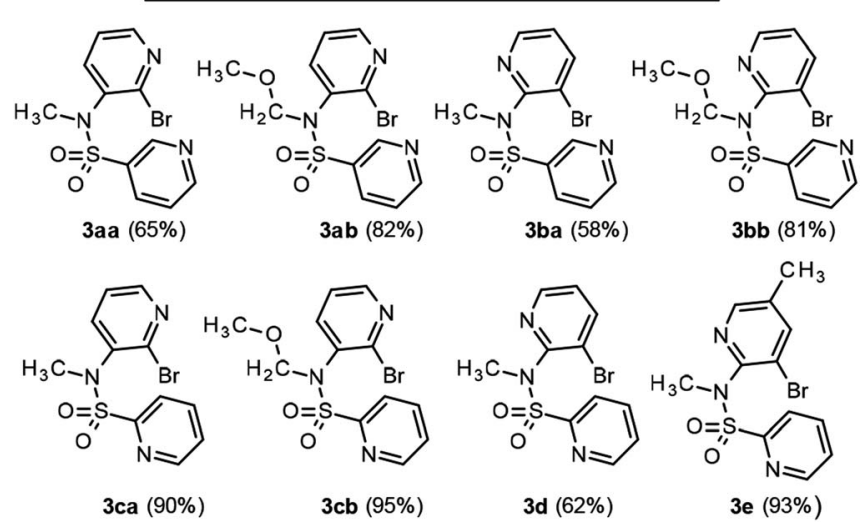

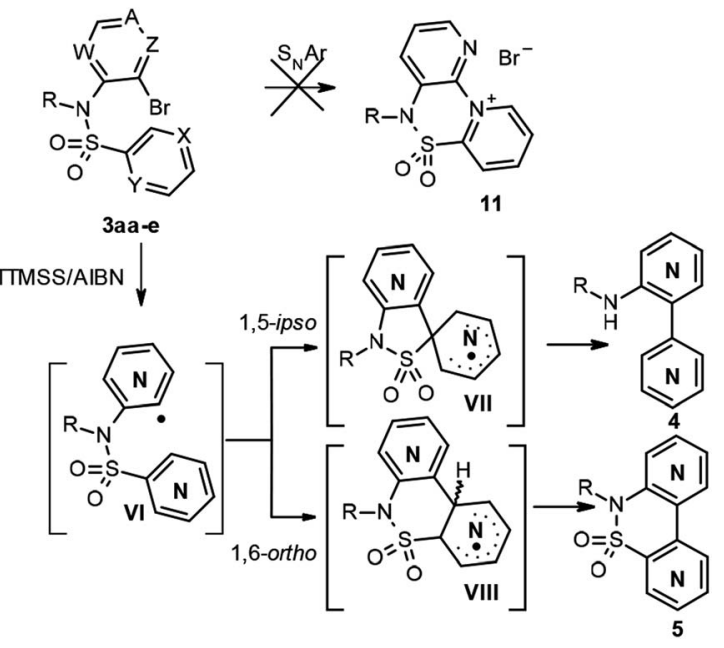

Scheme 7 Some alternative reaction pathways for the bromo sulfonamides 3 .

$\mathrm{S}_{\mathrm{N}} \mathrm{Ar}$ process to give the cyclic derivative $\mathbf{1 1}$ due to the nucleophilicity of the pyridine nitrogen and the favourable position of bromide, which can act as a good leaving group, on the other pyridine nitrogen. However, in accordance with previous reports, products 11 were never detected. The other pathways involve the initial formation of heteroaryl radical VI, which would evolve by $[1,5]$-ipso-addition to give the spirocyclic radical VII and then bipyridines 4 , and/or by [1,6]-ortho-addition, in different positions, depending on the starting compound $\mathbf{3}$, to give radical VIII and, subsequently, $\mathbf{5}$.

For the starting material 3 with the sulfonamide group in position $\mathrm{C} 3(\mathrm{X}=\mathrm{N}, \mathrm{Y}=\mathrm{CH}$; compounds 3aa-3bb), in all cases the initial radical VI undergoes a $[1,6]$-ortho-attack to yield compounds 5 , whereas the alternative [1,5]-ipso-attack was only detected in the case of sulfonamide 3aa, with product 4aa being obtained as a by-product of the reaction $(<20 \%$; Scheme 8$)$. The experimental evidence points to a trend in the reactivity depending on whether the $\mathrm{Br}$ substituent is positioned on either $\mathrm{C}^{\prime}$ (3aa and 3ab) or C3' (3ba and $\mathbf{3 b b}$ ) of the attacking pyridine. $^{16}$
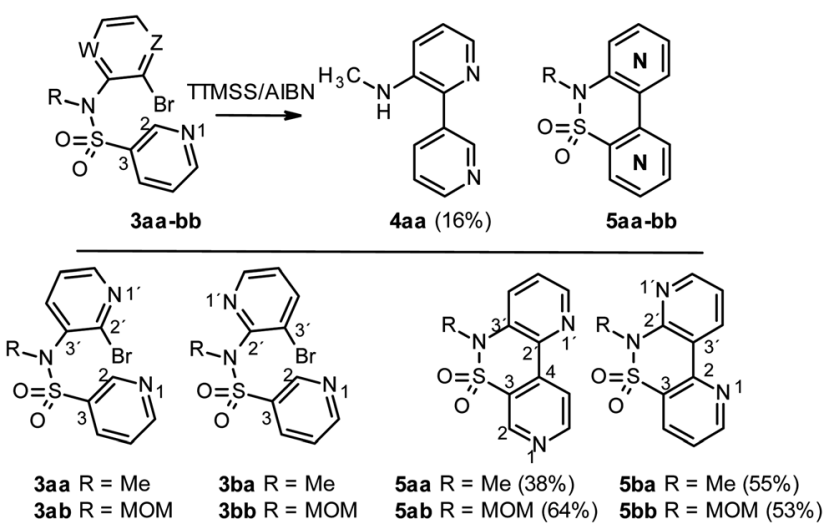

Scheme 8 Results in the preparation of compound 5aa-bb. 


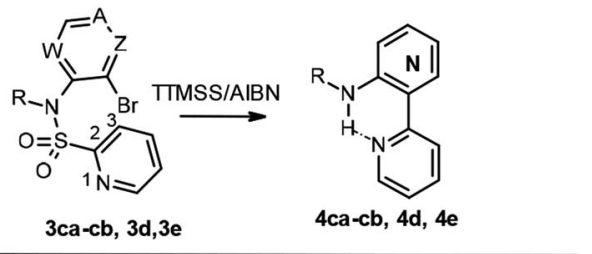

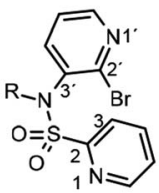

3ca $\mathrm{R}=\mathrm{Me}$ 3cb $\mathrm{R}=\mathrm{MOM}$

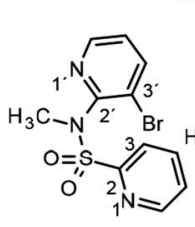

3d

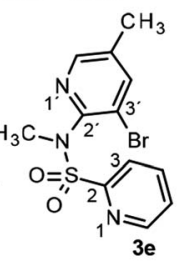<smiles>[R]N1C[n+]2ccccc2-c2ncccc21</smiles>

4ca $\mathrm{R}=\mathrm{Me}(74 \%)$ 4cb $R=H(64 \%)$

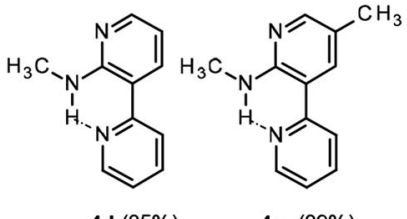

4d $(85 \%)$

4e $(89 \%)$

Scheme 9 Results in the preparation of compound $4 c a-b, 4 d$ and $4 e$

Thus, those substrates with a $\mathrm{Br}$ in the $\mathrm{C}^{\prime}$ position of the pyridine (3aa and $\mathbf{3 a b}$ ) yield the $\mathrm{C} 4$-substituted derivatives as the main products (5aa and $\mathbf{5 a b}$, respectively, Scheme 8) due to the repulsion generated by the proximity of the radical to the non-binding pairs of both nitrogens in the adduct intermediate. In contrast, for those with a $\mathrm{Br}$ in position $\mathrm{C}^{\prime}$ of the pyridine (3ba and 3bb), the main product results from the attack at $\mathrm{C} 2$, which yields products $5 \mathbf{b a}$ and $\mathbf{5 b} \mathbf{b}$, respectively.

Conversely, for compounds 3 with the sulfonamide group placed in position $\mathrm{C} 2(\mathrm{Y}=\mathrm{N}, \mathrm{X}=\mathrm{CH}$; compounds 3ca-b, 3d and 3e) and a Br substituent in positions $\mathrm{C}^{\prime}$ and $\mathrm{C}^{\prime}$ ' (Scheme 9), the initial radical VI undergoes [1,5]-ipso-attack to yield the spirocyclic radical VII and, subsequently, compounds 4. For the alternative $[1,6]$-ortho-attack, we were only able to detect traces of compounds $\mathbf{5}$ (if at all). The experimental data indicate that, irrespective of the position of the pyridine nitrogen in $\mathrm{N} 1^{\prime}$, the

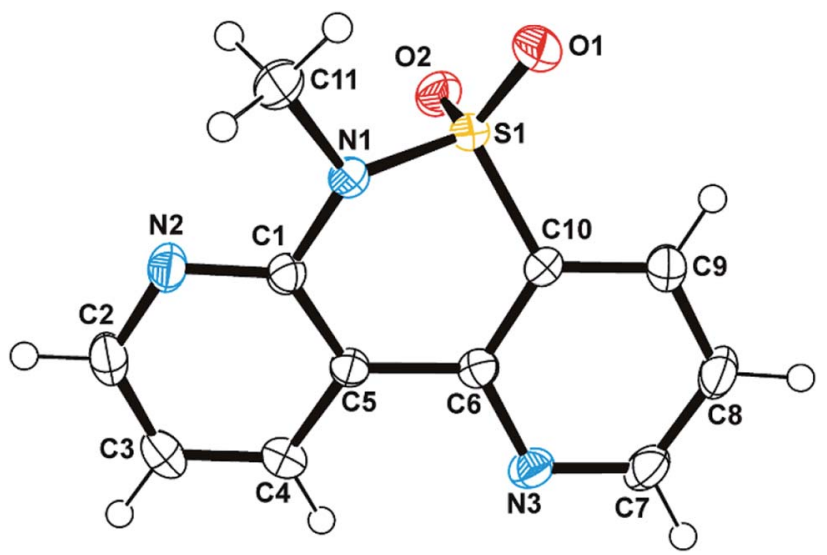

Fig. 3 ORTEP diagram for compound 5ba. Thermal ellipsoids are drawn at the $50 \%$ probability level. reaction evolves towards the formation of product $\mathbf{4}$ with an intramolecular hydrogen bond in all cases, with the primary or secondary amine acting as $\mathrm{H}$-donor and the pyridine $\mathrm{N} 1$ as $\mathrm{H}$ acceptor.

In order to check other referable cases, we tried to prepare sulfonamides $\mathbf{3}$ from the commercially available products 4-bromo-3-aminopyridine 7c and 3-bromo-4-aminopyridine 7d, but our attempts were unsuccessful. Notably, for compound $\mathbf{3 c b}$, which contains a MOM group in the starting material, a concomitant deprotection of MOM group was observed during work-up, thus giving easy access to the unsubstituted amine. ${ }^{17}$ These results are summarized in scheme 9.

The identity of these compounds was elucidated by NMR experiments and the structure of one of them (compound 5ba) unequivocally confirmed by X-ray crystallographic analysis (Fig. 3 and ESI $\dagger$ ).

\section{Conclusions}

In summary, our results show that intramolecular radical [1,5]ipso and [1,6]-ortho substitutions offer a method for the preparation of aminobipyridines or bipyridine sultams when a sulfonamide linker connects the attacking pyridyl radical to the pyridine under attack. For derivatives with a sulfonamide group at the C3-position of the starting pyridine, the [1,6]-ortho substitution product was identified in all cases. For substrates with the sulfonamide group at the C2-position, mainly aminobipyridines were obtained, being the leading event the formation of an intramolecular hydrogen bond between the primary or secondary amine as $\mathrm{H}$-donor, and the pyridine $\mathrm{N} 1$ as $\mathrm{H}$ acceptor. These sulfonamides with a MOM group in the starting material underwent deprotection of the MOM group during work-up, thus allowing easy access to the unsubstituted amine.

\section{Conflicts of interest}

There are no conflicts to declare.

\section{Acknowledgements}

We gratefully acknowledge financial support from FEDER and the Comunidad de Madrid (CAM, project B2017/BMD-3688 MULTI-TARGET\&VIEW-CM FEDER FUNDS), the Ministerio de Economia, Industria y Competitividad (project CTQ2017-85203P), Instituto de Salud Carlos III (FEDER funds, ISCIII RETIC REDINREN RD16/0009/0015 FEDER FUNDS) and the Universidad de Alcalá (CCG2017/EXP-021, CCG2018/EXP-008 and CCG2018/EXP-051). J. R. also thanks the Universidad de Alcalá for a predoctoral grant.

\section{Notes and references}

1 (a) Y. Zhou, S. Deng, S. Mai and Q. Song, Org. Lett., 2018, 20, 6161; (b) C. Chatgilialoglu, C. Ferreri, Y. Landais and V. I. Timokhin, Chem. Rev., 2018, 118, 6516; (c) K. Murakami, S. Yamada, T. Kaneda and K. Itami, Chem. Rev., 2017, 117, 9302; (d) F. Ujjainwalla, M. L. E. N. da 
Mata, A. M. K. Pennell, C. Escolano, W. B. Motherwell and S. Vazquez, Tetrahedron, 2015, 71, 6701; (e) T. Kawamoto, A. Sato and I. Ryu, Org. Lett., 2014, 16, 2111; $(f)$ H. Bonin, M. Sauthier and F.-X. Felpin, Adv. Synth. Catal., 2014, 356, 645; (g) A. Dewanji, S. Murarka, D. P. Curran and A. Studer, Org. Lett., 2013, 15, 6102; (h) S. Vaillard and A. Studer Radical arylations. Ed. C. Chatgilialoglu and A. Studer; Encyclopedia of Radicals in Chemistry, Biology and Materials 2012, vol. 2, p. 1059.

2 (a) F.-M. Werner and R. Covenas, Curr. Pharm. Des., 2019, 25, 396; (b) D. Chen, Q. Zhao and W. Liu, J. Ind. Microbiol. Biotechnol., 2019, 46, 459; (c) M. Chen, Y. Zhang, Y. Du, Q. Zhao, Q. Zhang, J. Wu and W. Liu, Org. Biomol. Chem., 2017, 15, 5472; (d) P. M. Garcia-Barrantes, J. R. Harp and C. W. Lindsley, Tetrahedron Lett., 2016, 57, 2194; (e) Y. Zhu, M.-E. Picard, Q. Zhang, J. Barma, X. M. Despres, X. Mei, L. Zhang, J.-B. Duvignaud, M. Couture, W. Zhu, R. Shi and C. Zhang, Chem. Sci., 2016, 7, 4868; (f) P. Fu, P. Liu, X. Li, Y. Wang, S. Wang, K. Hong and W. Zhu, Org. Lett., 2011, 13, 5948; (g) K. F. Croom and M. A. A. Siddiqui, Drugs, 2009, 69, 1513.

3 (a) S. Samiee and S. Taghvaeian, Appl. Organomet. Chem., 2019, 33, 1; (b) X. Long, Y. Gao, H. Tian, C. Dou, D. Yan, Y. Geng, J. Liu and L. Wang, Chem. Commun., 2017, 53, 1649; (c) Z. Zhang, Z. Ding, X. Long, C. Dou, J. Liu and L. Wang, J. Mater. Chem. C, 2017, 5, 6812; (d) O. V. Shabunina, D. Y. Kapustina, A. P. Krinochkin, G. A. Kim, D. S. Kopchuk, G. V. Zyryanov, F. Li and O. N. Chupakhin, Mendeleev Commun., 2017, 27, 602.

4 (a) S. Feng, S. Li, J. Li and J. Wei, Org. Chem. Front., 2019, 6, 517; (b) Y.-N. Ma, C.-Y. Guo, Q. Zhao, J. Zhang and X. Chen, Green Chem., 2018, 20, 2953; (c) E. D. Nacsa and T. H. Lambert, Org. Chem. Front., 2018, 5, 64; (d) S. K. Chattopadhyay, Synth. Commun., 2018, 48, 3033; (e) B. Maheshwar Rao, J. S. Yadav, B. Sridhar and B. V. Subba Reddy, Org. Biomol. Chem., 2018, 16, 5163; $(f)$ S. Debnath and S. Mondal, Eur. J. Org. Chem., 2018, 933; (g) T. S. Virk,
N. V. Ilawe, G. Zhang, C. P. Yu, B. M. Wong and J. M. W. Chan, ACS Omega, 2016, 1, 1336; (h) W. D. Guerra, R. A. Rossi, A. P. Pierini and S. M. Barolo, J. Org. Chem., 2016, 81, 4965; (i) Y.-Y. Han, H. Wang and S. Yu, Org. Chem. Front., 2016, 3, 953; (j) K. C. Majumdar and S. Mondal, Chem. Rev., 2011, 111, 7749.

5 J. Recio, A. Perez-Redondo, J. Alvarez-Builla and C. Burgos, Org. Chem. Front., 2019, 6, 3300.

6 (a) M. L. E. N. da Mata, W. B. Motherwell and F. Ujjainwalla, Tetrahedron Lett., 1997, 38, 141; (b) M. L. E. N. da Mata, W. B. Motherwell and F. Ujjainwalla, Tetrahedron Lett., 1997, 38, 137.

7 A. Ryokawa and H. Togo, Tetrahedron, 2001, 57, 5915.

8 R. Yamasaki, A. Tanatani, I. Azumaya, S. Saito, K. Yamaguchi and H. Kagechika, Org. Lett., 2003, 5, 1265.

9 (a) M. Camacho-Artacho, V. Abet, L. M. Frutos, F. Gago, J. Alvarez-Builla and C. Burgos, J. Org. Chem., 2011, 76, 1452; (b) A. Sanchez, A. Nunez, J. Alvarez-Builla and C. Burgos, Tetrahedron, 2004, 60, 11843.

10 A. Beltran, E. Alvarez, M. M. Diaz-Requejo and P. J. Perez, Adv. Synth. Catal., 2015, 357, 2821.

11 E. Dupont-Passelaigue, I. Le Roy and C. Pignier, PCT. Int. Appl., WO 2012069503 A1, 2012.

12 M. Birch, G. E. M. Sibley, D. Law and J. D. Oliver, PCT. Int. Appl., WO 2009144473 A1, 2009.

13 W. T. Caldwell, F. T. Tyson and L. Lauer, J. Am. Chem. Soc., 1944, 66, 1479.

14 (a) S. Blanchard, I. Rodriguez, C. Kuehm-Caubere, P. Renard, B. Pfeiffer, G. Guillaumet and P. Caubere, Tetrahedron, 2002, 58, 3513; (b) G. Abbiati, E. M. Beccalli, G. Broggini, G. Paladino and E. Rossi, Synthesis, 2005, 2881.

15 C. Chatgilialoglu, C. Ferreri, Y. Landais and V. I. Timokhin, Chem. Rev., 2018, 118, 6516.

16 F. Filace, P. A. Sanchez-Murcia, D. Sucunza, A. PerezRedondo, J. Alvarez-Builla, F. Gago and C. Burgos, Eur. J. Org. Chem., 2016, 1891.

17 L. Kaczmarek, Bull. Pol. Acad. Sci., Chem., 1985, 33, 401. 